\title{
Compound conditioning of the rabbit's nictitating membrane response: Test trial manipulations
}

\author{
E. JAMES KEHOE and BERNARD G. SCHREURS \\ University of New South Wales, Kensington, Australia
}

\begin{abstract}
The acquisition of the rabbit's nictitating membrane response to a tone + light compound and its components was examined in four groups of rabbits. Two groups received separate test presentations of the tone and light throughout training. In one group, the test trials were reinforced. In the other two groups, test trials, both reinforced and nonreinforced, were confined to the last 3 days of training. In all groups, the animals attained high levels of responding to the compound and showed minimal levels of responding on both tone and light test trials. The inclusion of test trials, whether reinforced or nonreinforced, failed to significantly alter the levels of responding to the compound, tone, or light.
\end{abstract}

In previous studies using reinforced tone + light compound stimuli, differentiation of the compound from its components has required either prolonged training with the compound (Bellingham \& Gillette, 1981; Gillette \& Bellingham, 1982; Gray \& Lethbridge, 1976) or explicit differential reinforcement of the compound and its components (Kehoe \& Gormezano, 1980). However, some researchers using reinforced compound presentations have found that large differences in the levels of responding to the compound and to its components can emerge relatively early in training (Kehoe, 1982, in press; Kehoe \& Schreurs, in press; Wickens, Nield, Tuber, \& Wickens, 1970). In particular, at conditioned stimulus (CS)unconditioned stimulus (US) intervals somewhat longer than the optimal value for conditioned response (CR) acquisition, the animals attained virtually $100 \%$ CRs to the compound but showed little or no responding on either tone or light test trials. From the most methodologically rigorous perspective (Baker, 1968), the compound conditioning procedure used by Wickens et al. (1970) and by Kehoe (1982, in press) provided the opportunity for explicit differential conditioning via the use of unreinforced test trials for the components. Although the number of reinforced compound trials presented in these studies outnumbered the component presentations by a margin as large as 10 to 1 , differential conditioning to a compound and its components might require only a relatively small number of unreinforced component presentations. However, in a cat paw flexion preparation, Wickens et al. (1970, Experiment 2) found that the presence or absence of unreinforced component test trials early in training had

This research was supported by Grant A28315236 from the Australian Research Grants Committee. The authors thank Maree Bell, John Hogan, and Patricia Spicer for their assistance in collecting the data. Requests for reprints should be sent to E. J. Kehoe, School of Psychology, University of New South Wales, Kensington, NSW, 2033, Australia. little discernible effect on the large difference between responding to a compound and its components when unreinforced tests were conducted at the end of training. In the rabbit eyeblink response preparation, Saavedra (1975, Experiment 2) conducted component testing by reinforcing the test trials for half her subjects and not reinforcing the test trials for the other half of her subjects. Regardless of whether the test trials were reinforced or not, she found that her subjects attained $100 \%$ CRs on compound trials and approximately $50 \%$ CRs on component test trials. In light of these observations, the present experiment was conducted in order to determine whether the presence of component test trials and/or their lack of reinforcement played a role in the near-perfect differentiation between the compound and components seen in the rabbit nictitating membrane response (NMR) preparation (Kehoe, in press; Kehoe \& Schreurs, in press). Specifically, the present experiment combined the procedures used by Wickens et al. (1970) and Saavedra (1975).

\section{METHOD}

\section{Subjects}

The subjects were 28 naive female albino rabbits (Oryctolagus cuniculus), each 70-80 days old and weighing approximately $1.5 \mathrm{~kg}$. The animals had free access to food and water in their home cages.
Apparatus
The apparatus and recording procedure for the nictitating membrane response were patterned after those of Gormezano (1966) and are detailed by Kehoe, Feyer, and Moses (1981). The CSs were (1) an 800-msec, $1,000-\mathrm{Hz}, 92-\mathrm{dB}$ (SPL) tone superimposed on an ambient noise level of $81 \mathrm{~dB}$, and (2) an $800-\mathrm{msec}, 20-\mathrm{Hz}$ flashing of the neon tube that served as the houselight. The US was a 50-msec, 3-mA, 50- $\mathrm{Hz}$ ac shock delivered via stainless steel Autoclip wound clips positioned $10 \mathrm{~mm}$ apart and $15 \mathrm{~mm}$ posterior to the dorsal canthus of the right eye. The CS-US interval was $800 \mathrm{msec}$. The sequence and timing of stimulus events were controlled by an Apple II computer equipped with interfaces and soft- ware developed by Scandrett and Gormezano (1980).
The apparatus for transducing movements of the nictitating membrane differed in some respects from that described in previous reports. No 
straps were used to restrain the external eyelids. To monitor movements of the nictitating membrane, a small tinned copper wire hook was attached to a silk loop sutured in the nictitating membrane of the rabbit's right eye. The other end of the hook contained a loop which fitted over another hook at the end of an L-shaped piano wire lever, which operated a photoelectric transducer (see Kehoe et al., 1981). The signal from the transducer was amplified and transmitted to an analog/digital converter installed in the computer (Scandrett \& Gormezano, 1980).

\section{Procedure}

All rabbits received 1 day of preparation, 2 days of recovery, 1 day of adaptation, 7 days in Stage 1, and 3 days in Stage 2. On the preparation day, hair surrounding the rabbit's right eye was removed, a small loop of silk (000 Dynex) was sutured into the nictitating membrane, and the animals were returned to their home cages for 2 days of recovery. On the adaptation day, the animals were placed in the conditioning apparatus for $70 \mathrm{~min}$, but neither a CS nor a US was presented.

Following adaptation, the animals were assigned randomly to one of four groups. All groups received reinforced compound trials every day throughout Stages 1 and 2. In addition, all groups received test trials with the tone and light during Stage 2. The groups varied in terms of (1) whether test trials were present $(\mathrm{P})$ or absent $(\mathrm{A})$ during Stage 1 and $(2)$ whether the test trials were reinforced $(+)$ or nonreinforced $(-)$. Accordingly, the groups were designated $\mathrm{P}+, \mathrm{P}-, \mathrm{A}+$, and $\mathrm{A}-$. Thus, for Groups $P+(n=8)$ and $P-(n=8)$, each day in both stages contained the 60 reinforced compound trials $(\mathrm{C}+)$ interspersed with three test trials each of the compound $(C)$, tone $(T)$, and light $(\mathrm{L})$, which were reinforced in Group P+ and unreinforced in Group P-. For Groups A+ $(n=4)$ and $A-(n=8)$, each day of Stage 1 training entailed the 60 reinforced compound presentations and only the test trials for the compound. During Stage 2, Groups A+ and A- received the same trial schedules as did Groups $\mathrm{P}+$ and $\mathrm{P}-$, respectively. A test trial was presented every sixth trial in both Stage 1 and Stage 2. When component test trials were given, the sequence of test trials was CTLLCTTLC on odd days and TLCLCTCTL on even days. For Groups A+ and Ain Stage 1, the tone and light test trials were replaced by "blank" trials that contained no programmed stimuli. The mean intertrial interval (ITI) was $60 \mathrm{sec}$ (range 40-80 sec).

A conditioned response (CR) was defined as any extension of the nictitating membrane exceeding $.5 \mathrm{~mm}$ which occurred following the onset of the CS but prior to its termination. Unless otherwise noted, planned contrasts were used to analyze the data and the rejection level was set according to a Type 1 error rate of .05 .

\section{RESULTS}

\section{Stage 1}

All four groups showed a steady rate of CR acquisition on reinforced compound trials, reaching mean levels between $73 \%$ and $81 \%$ CRs on the last day of Stage 1 training. The statistical analysis confirmed the growth in CRs, because there were significant linear $[F(1,24)=104.55]$ and quadratic $[F(1,24)=10.63]$ trends across days of training. The differences among groups were small and failed to reach statistical significance. For example, the overall mean levels of responding on compound trials for Groups P+, P-, At, and A- were $47 \%, 54 \%, 50 \%$, and $56 \% \mathrm{CRs}$, respectively $(F \mathrm{~s}<1)$.

Figure 1 shows the percentage of CRs on compound, tone, and light trials for Groups $\mathrm{P}+$ and $\mathrm{P}-$ as a function of days of training in Stage 1. As may be apparent in Figure 1, the level of responding on compound trials was significantly higher than the level of responding on either tone $[F(1,14)=23.37]$ or light test trials $[F(1,14)=$ 30.63]. Any apparent differences between groups failed to attain signficance.

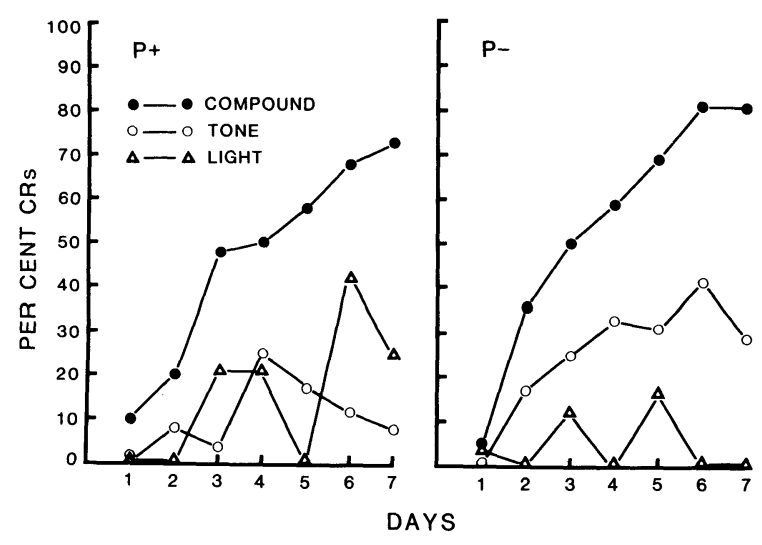

Figure 1. Mean percentage $C R s$ to the compound, tone, and light in Groups $\mathbf{P}+$ and $\mathbf{P}-$ as a function of days in Stage 1 .

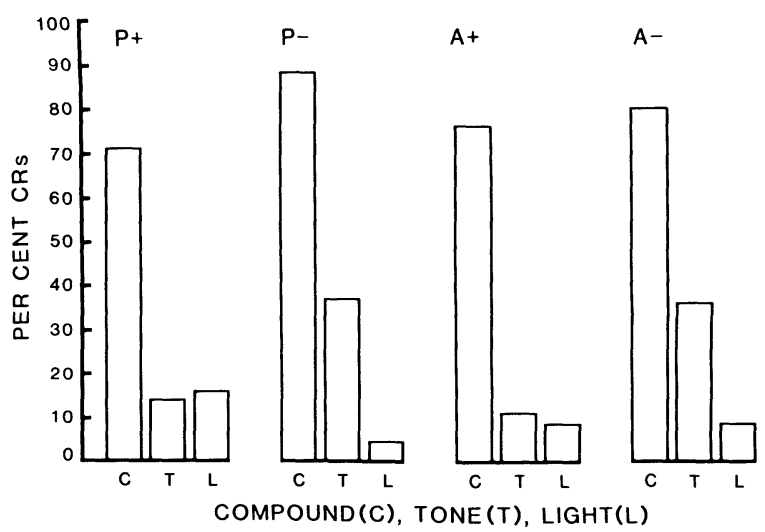

Figure 2. Mean percentage CRs to the compound, tone, and light in Groups $\mathbf{P}+, \mathbf{P}-, \mathbf{A}+$, and $\mathbf{A}-$ in Stage 2.

\section{Stage 2}

Figure 2 presents overall mean percentage of CRs on compound, tone, and light test trials during Stage 2 for each of the four groups. Inspection of the figure reveals, and statistical analysis confirmed, that for all groups, the level of responding to the compound was substantially higher than responding to either tone $[F(1,24)=76.88]$ or light $[F(1,24)=239.19]$. In addition, the level of responding to the tone was significantly higher than the level of responding to the light $[F(1,24)=7.92]$. In comparisons among groups, the level of responding to the tone appeared to be higher in Groups $\mathrm{P}-$ and $\mathrm{A}-$ than in Groups $\mathrm{P}+$ and $\mathrm{A}+$. However, that difference and all other apparent differences among groups failed to reach significance $[F(1,24)=3.39, p<.10]$.

\section{DISCUSSION}

The present results confirmed earlier findings that the level of $C R$ acquisition to a compound can reach high levels while the level of responding to both the tone and light remain at low levels (Kehoe, in press; Kehoe \& Schreurs, in press; Wickens et al., 1970). Moreover, in keeping with the findings of Wickens et al. (1970) and Saavedra (1975), the present results indicated that the presence of test trials and/or 
their reinforcement had little discernible impact on differences among the levels of responding to a compound and its components. However, the apparent failure of test trials to alter the levels of responding to a compound and its components is undoubtedly limited to schedules in which test trials are a small proportion of the total number of trials. Larger proportions of component presentations relative to compound presentations have had a demonstrable impact on the levels of responding to a compound and its components. For example, Kehoe and Schreurs (in press, Experiment 1) obtained increases in differentiation between a compound and its components by reducing the number of reinforced compound trials per day from 60 to 24 , while increasing the number of unreinforced component presentations per day from 3 to 12 . Likewise, high proportions of reinforced test trials can alter the relative levels of responding to a compound and its components. Specifically, Kehoe (in press, Experiment 2) varied the proportion of reinforced compound trials to reinforced component trials. He found that the level of responding to the compound stayed relatively constant, but the level of responding to the components rose to a level nearly as high as that of the compound when the proportion of component trials equaled that of compound trials.

\section{REFERENCES}

BAKer, T. W. (1968). Properties of compound conditioned stimuli and their components. Psychological Bulletin, 70, 611-625.

Bellingham, W. P., \& Gillette, K. (1981). Spontaneous configuring to a tone-light compound using appetitive training. Learning \& Motivation, 12, 420-434.

Gillette, K., \& Bellingham, W. P. (1982). Loss of within-compound flavour associations: Configural preconditioning. Experimental Animal Behaviour, 1, 1-17.

Gormezano, I. (1966). Classical conditioning. In J. B. Sidowski (Ed.), Experimental methods and instrumentation in psychology. New York: McGraw-Hill.
Gray, T., \& Lethbridge, D. A. (1976). Configural conditioning in the CER: Loss of element strength after repeated reinforced compound CS trials. Learning \& Motivation, 7, 532-539.

KeHOE, E. J. (1982). Overshadowing and summation in compound stimulus conditioning of the rabbit's nictitating membrane response. Journal of Experimental Psychology: Animal Behavior Processes, 8, 313-328.

KEHOE, E. J. (in press). Summation and configuration in conditioning of the rabbit's nictitating membrane response to compound stimuli. Journal of Experimental Psychology: Animal Behavior Processes.

Kenoe, E. J., Feyer, A., \& Moses, J. L. (1981). Second-order conditioning of the rabbit's nictitating membrane response as a function of the CS2-CS1 and CS1-US intervals. Animal Learning \& Behavior, 9, 304-315.

Kehoe, E. J., \& Gormezano, I. (1980). Configuration and combination laws in conditioning with compound stimuli. Psychological Bulletin, 87, 351-378.

Kehoe, E. J., \& SChreurs, B. G. (in press). Compound-component differentiation as a function of CS-US interval and CS duration in the rabbit's conditioned nictitating membrane response. Animal Learning \& Behavior.

SaAVEdRa, M. A. (1975). Pavlovian compound conditioning in the rabbit. Learning \& Motivation, 6, 314-326.

SCANDRETT, J., \& GoRmEZANO, I. (1980). Microprocessor control and A-D data acquisition in classical conditioning. Behavior Research Methods \& Instrumentation, 12, 120-125.

Wickens, D. D., Nield, A. F., Tuber, D. S., \& Wickens, C. D. (1970). Classically conditioned compound-element discrimination as a function of length of training, amount of testing and CS-UCS interval. Learning \& Motivation, 1, 95-109.

(Manuscript received for publication August 29, 1985.) 